\title{
Simulative Study into the Development of a Hybrid HVDC System Through a Comparative Research with HVAC: a Futuristic Approach
}

\author{
Ram S. Narayan \\ Electrical Engineering Department \\ National Institute of Technology, \\ Calicut, India
}

\author{
Shilpa Mohan \\ Electrical Engineering Department \\ National Institute of Technology \\ Calicut, India
}

\author{
K. Sunitha \\ Electrical Engineering Department \\ National Institute of Technology, \\ Calicut, India \\ karakkadsunitha@gmail.com
}

\begin{abstract}
High Voltage Direct Current Transmission (HVDC) is considered a better solution for bulk long distance transmissions. The increased use of HVDC is a result of its advantages over the HVAC systems and especially of its fault stability nature. A better solution is proposed by using a Voltage Source ControlledHVDC as one of the infeed for the Multi-Infeed HVDC (MIDC or MI-HVDC) systems. The main advantage with the VSC converter is its flexible power control which enhances the stability of the MIDC systems. In this paper, the behavior of an HVDC system is compared with that of an HVAC during faults. A Hybrid HVDC system that includes a LCC as a rectifier unit and a VSC converter as the inverter is being proposed. It is considered suitable for MIDC systems and particularly for supplying a weak AC system. The performance of the system during steady state and transient conditions for all the proposed topologies including HVDC, HVAC and Hybrid HVDC are studied in MATLAB/SIMULINK. All of the proposed control strategies are evaluated via a series of simulation case studies.
\end{abstract}

Keywords-High Voltage Direct Current; HVDC; HVAC; Transmission System; HYBRID; Fault; Transmission; Power

\section{INTRODUCTION}

The rally for direct current (dc) transmission, particularly, for long-distance power transport started in 1954 when ASEA, a predecessor of $\mathrm{ABB}$, connected the island of Gotland to mainland Sweden with high-voltage direct-current (HVDC) lines, even though HVDC transmission was considered as a power transmission option since 1950s [11]. HVDC found to be a seemingly convincing solution to a majority of problems and supported power transmission between asynchronous grids and bulk long distant power transport with reduced losses. The main reason for the wide acceptance of HVDC over HVAC systems is due to the unmatchable quality of HVDC systems to operate with flexibility [2]. A non-exhaustive list of advantages of HVDC over HVAC are: reduced corona loss, reduced insulation requirement, diminishing voltage drops, economically viable cost of towers, insulators, poles and conductors, and most importantly, the elimination of skin effect [4]. Nowadays, a single AC network is housing a large number of High Voltage DC transmission links with near electrical proximity. This system of integrating numerous High Voltage
DC links to feed power into a single AC network at different points is known as "Multi-Infeed High Voltage Direct Current system" (MIDC) [1]. A MIDC system includes either a shared/common AC bus or buses which are in close proximity as shown in Figure 1. There exist some practical examples where more than one HVDC transmission are linked towards the very same AC network with close electrical proximity. A very common setting of such a system is the multi-bipole infeed connected to the same place in the network. This will in turn call for mutual interferences between the two inverters which results in the commutation failure. The scenario stands good only if the converters terminate at the same place in the network and rather if they terminate at separate places (by electrically separating the inverters through impedances in the network), then we could always reduce the interaction. The afore said problems in the multi-bipoles ending up at the same place could be safely reduced with the implementation of multi-infeed HVDC systems. These advantages of multi-infeed systems motivated us to propose a hybrid HVDC technology suitable for such systems.

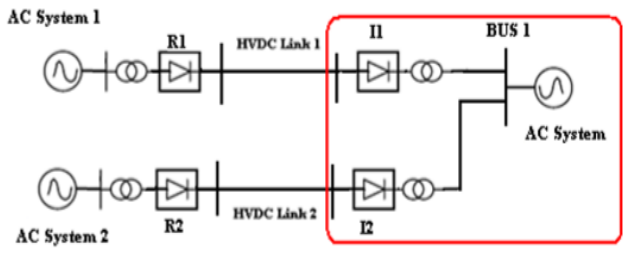

Fig. 1. MI-HVDC system

\section{THE EFFECT OF FAULT CURRENT IN POWER SYSTEMS}

Short Circuit current (also known as "Fault Current") arises as soon as a fault occurs in a power system. Fault Current is nothing but essentially a massive flow of current through an electric circuit. The effects of short circuit current could be catastrophic mostly damaging the equipment and completely destroying its insulation system. Sometimes they may also lead to power surges in the system or even administer an electric shock by charging the device. Faults can be classified into 
symmetrical and asymmetrical ones. In symmetrical faults, all the phases are affected with the same magnitude and effect. But in practice only $5 \%$ of faults are symmetrical and asymmetrical faults occur in abundance where only one (mostly) or two phases are affected asymmetrically. But the analysis of asymmetrical faults is always a headache due to their misaligned distribution of current among the phases and thereby forcing us to assume equal distribution of currents among all the three phases [7-10]. Unbalanced faults can be broadly classified into three common types namely line-to-line, line-to-ground and double-line-to-ground faults. In power systems, generators are encountered with high level fault currents subjecting the generator to experience stress beyond its design limits and eventually a temperature rise. Some more direful consequences of fault currents are the sudden loss of loads, fault clearances and unbalanced flux densities distorting the air gap torques. The consequences are not alone related to these electrical stresses but may also create some mechanical unbalances resulting in the amplification of oscillations encountering in the shaft.

The main aim behind the reduction of the magnitude of fault currents is not only to counter-effect these dire outcomes of fault currents but also to optimize the size and cost of circuit breakers thereby increasing the flexibility of operation of circuit breakers. There are a lot issues to be concerned in case of a MI-HVDC system. Some of the major concerns include huge over-voltages, commutation failure risk, instabilities occurring in voltage and power and AC/DC fault recovery [12]. The above-said problems will get aggregated particularly when MI-HVDC is connected into a weak system.

An AC system is considered in terms of a factor called Short Circuit Ratio (SCR) which is described in (1), as the ratio of short circuit MVA (SCMVA) of the AC system at the converter terminal AC bus to the rated DC terminal power $(\mathrm{Pdc})$.

$$
\mathrm{SCl} \mathrm{SCR}=\mathrm{V}_{1}^{2} /\left(\mathrm{Z}_{\mathrm{s}} * \mathrm{P}_{\mathrm{dc}}\right)
$$

A strong system can be defined as a system possessing an SCR greater than 3 whereas if SCR lies between 2 and 3, the system is moderately strong or weak. The system can be termed to be very weak, if SCR is less than 2 .

It can be seen from the simulation patterns that strong systems tend to be dynamically stable while weaker systems are more prone to the risk of dynamic instability. This could result in huge deflections in voltage and other parameters even for a very small disturbance. The fore-said effect of unstable condition becomes a major concern when LCC based HVDC systems are used. But recent trends are shifting the MI-HVDC systems from using LCC based HVDC systems to VSC-based systems. VSC based HVDC transmission technology is more preferred mainly because of its advantages like independent control of active and reactive power, possibility to invert into a weak or passive AC network, reduced harmonics and good controllability [6].

The demerits of the VSC based HVDC system lies in case of cost and high frequency switching losses which are absent in
LCC-HVDC. This results in lesser rating of voltage and power for VSC based HVDC. To overcome these problems faced by VSC based HVDC systems, a HYBRID HVDC system can be utilized [1]. The major plus point of a HYBRID HVDC system is that it is having the merits of both LCC and VSC based HVDC systems and can eradicate the demerits of both effectively. The LCC system helps in optimizing the cost and the VSC system plays a role in reducing the issues with commutation failures.

In this paper a Hybrid HVDC system is considered consisting of both LCC and VSC converters, which can be used to integrate with conventional LCC-HVDC inverting into a very weak AC system. The main advantage of Hybrid HVDC is in its use in MI-HVDC systems. HYBRID systems are preferred for unidirectional power transmission scenarios, like transmitting power to estranged islands and remote load centers, particularly where it is difficult to construct new transmission lines. As like in VSC HVDC systems, here also the control strategies for the rectifier and inverter are preferred and implemented using Proportional Integral (PI) controllers.

\section{SIMULATION}

\section{A. HVAC Transmission System}

A three-phase HVAC transmission system is simulated using MATLAB as in Figure 2, transmitting power between two stations through a $300 \mathrm{~km}$ Pi section line. As part of the compensation requirements, series capacitors are provided to improve the total transmitted power capacity. The series reactance actually decreases the transfer reactance between the buses to which the line is connected and thus increases the maximum power transmission capability. This in turn effects in decreasing the effective reactive power losses [4]. Three phase breakers are provided at both ends for protection purposes and the measurements are taken from the buses at both sides. A three-phase series RLC load is also provided at one side for dump loading purposes. A single phase to ground fault have also been simulated at the transmission end of the system for contingency analysis purposes.

\section{B. HVDC Transmission System}

The simulation model of a hybrid high-voltage direct current (HVDC) transmission system using a 6-pulse thyristor based universal bridge converter, transmitting power between two stations through a $300 \mathrm{~km}$ DC transmission line. A 500 MW $(250 \mathrm{kV}, 2 \mathrm{kA})$ DC inter-connection is used for transmitting power from a $315 \mathrm{kV}, 5000$ MVA AC network. The network is simulated as an LLR damped equivalent (impedance angle of 80 degrees at $60 \mathrm{~Hz}$ and 3rd harmonic). The converter transformer and the rectifier are modeled using the already available Universal Transformer and Universal Bridge blocks. The converter used here is a 6-pulse rectifier. It is inter-connected using a $300 \mathrm{~km}$ distributed parameter line with the help of a $0.5 \mathrm{H}$ smoothing reactor LsR. The main purpose behind using smoothing reactor is to provide protection against intermittent current and fault currents, and also to prevent resonance in the DC circuits [3-5]. In this simulation, the inverter is simulated as a simple DC voltage 
source in series with a diode (for unidirectional conduction) and smoothing reactor LsI. The reactive power required by the converter is provided by a set of filters (C bank plus 5th, 7th and high pass filters; total 320 Mvar). The voltages being sent to the synchronized system are filtered using a second order band pass filter. The parameters for both the simulation are kept the same in order to get a more clarified analysis of the system under faulted conditions. A Hybrid HVDC system with power rating of $1000 \mathrm{MW}$ and a DC rating of $500 \mathrm{kV}$ is considered here. The other Hybrid HVDC system parameters are identical with the CIGRE HVDC Benchmark model. The SCR of the combined system of $1300 \mathrm{MW}$ is 1.92 which corresponds to a very weak AC network. A DC link of $300 \mathrm{~km}$ length with specified inductance and capacitance values is used in the simulation.

The 1000 MW Hybrid HVDC system as shown in Figure 3 has LCC at the rectifier side and VSC at the inverter side. The $\mathrm{AC}$ rms voltage at the rectifier side is same at both the rectifier and inverter sides as $345 \mathrm{kV}$. The simulations are run for $2 \mathrm{sec}$, giving ample time for the system to attain its steady state. The control scheme utilized for LCC rectifier of Hybrid system is constant current control while DC and AC voltage control used for the VSC inverter of Hybrid system.

\section{RESUlts}

\section{A. HVAC Transmission System}

Figure 4 shows the simulation output of HVAC transmission system under normal and faulted conditions. The system attains the steady state condition quickly. A DC fault is applied to the system at 0.5 seconds for 0.01 seconds duration. Figure 4 shows that the system tries to reach a new steady state condition on the occurrence of a fault in a slow pace and it almost takes 0.5 seconds to arrive at the new steady state position after fault clearance.

\section{B. HVDC Tranmission System}

Figures 5 and 6 show the simulation output for the HVDC transmission system. Figure 7 represents the output of the HVDC system with uncontrolled rectifier without faults under steady state performance. The system reaches a steady state position quickly, taking only 0.1 seconds. The DC side voltages and currents have been held constant using both AC side filters and DC side filters. Figure 5 corresponds to the faulted condition performance of HVDC system with thyristor controlled rectifier for a DC side fault. The same fault of 0.01 seconds duration as given to the HVAC system was applied to this system also at the same position of 0.5 seconds. The DC side voltage was then suddenly reduced to zero and the DC side current raised anomaly corresponding to the fault. The system reached a new steady state after 0.3 seconds of fault clearance. While observing Figures 4-6, we can observe that the HVDC system was affected less severely compared to the HVAC system of same specifications under similar conditions. From Figure 4, we get a picture about the intensity and impact of the fault current in HVAC systems when compared with HVDC system of similar dimensions and specifications. The effect of single-line-to-ground fault is observed at the sending end of voltage and current waveforms of HVAC system as they get distorted deviating from its normal position even though the fault occurs at the receiving end. Also, this causes a disturbance among the phase angles between the phases. For the same fault condition, sending end voltage and current waveforms of the HVDC transmission system are in approximate proper position. Here, the current waveforms seem to be disturbed because of the 6 pulse converter whereas this will not affect the overall performance of the system.

\section{Steady State and three-phase-to-ground fault}

The proposed HVDC system reaches the stable steady state at $0.5 \mathrm{sec}$. The DC link voltage and current at inverter side of HVDC attains the standard magnitude at around 0.5 seconds as shown in Figures 7 and 8. Three-phase-to-ground fault at the rectifier side of the HVDC was simulated during $1.0 \mathrm{sec}$ for a duration of $0.05 \mathrm{sec}$ and the results are depicted as shown in Figures 9 and 10. Here, a considerable improvement in DC voltage and current transients of the system has been observed, during the fault. There has been an increment of the rectifier alpha order to a maximum value and a decrement in the inverter extinction angle. The system achieves steady state within $0.25 \mathrm{sec}$ after the fault is cleared and the recovery is again fast. The performance of DC side and AC side inverters were almost similar to that of the single phase faults. The severity of fault disturbances were not found to be increased in case of three phase faults, as seen in conventional HVDC systems.

\section{DISCUSSION \& CONCLUSION}

This paper initially performs a 'fault current' analysis and a comparison study between HVAC and HVDC power transmission systems. The fault analysis was conducted for both HVAC and HVDC topologies. The interpretation of the results confirms the reduced fault level and impact in the HVDC system. A hybrid HVDC system consisting of LCC at the rectifier side and an VSC at the inverter side has been proposed for a very weak AC network and validated. The system steady state response and the performance of the system under various faulted conditions were simulated to get a complete picture of its behavior. The system performance under steady state and AC fault conditions were also studied. A conclusion can be drawn that there has been a considerable improvement in the transient performance of the MI-HVDC system under AC fault conditions. This proves the credibility of the hybrid system which utilizes the merits of both LCC and VSC system and seems to be a better solution to MI-HVDC systems inverting into a weak AC network.

The DC voltages in this model seem to be distributed unevenly among the HVDC links depending upon the nominal voltages. There had been some ripple observed in the DC side voltages of the system which comes as a result of circulating currents present in the converter, and this can be decreased by utilizing another modulation strategy or by using a huge capacitor across the converter arms. When a single-phase to ground fault has been applied at the rectifier side of the model, harmonic disturbances arise in the voltages and currents due to the unbalance of the fault. The LCC has not suffered from 
failure of commutation in the inverter. A three-phase to ground fault has been applied at the rectifier side of the model.

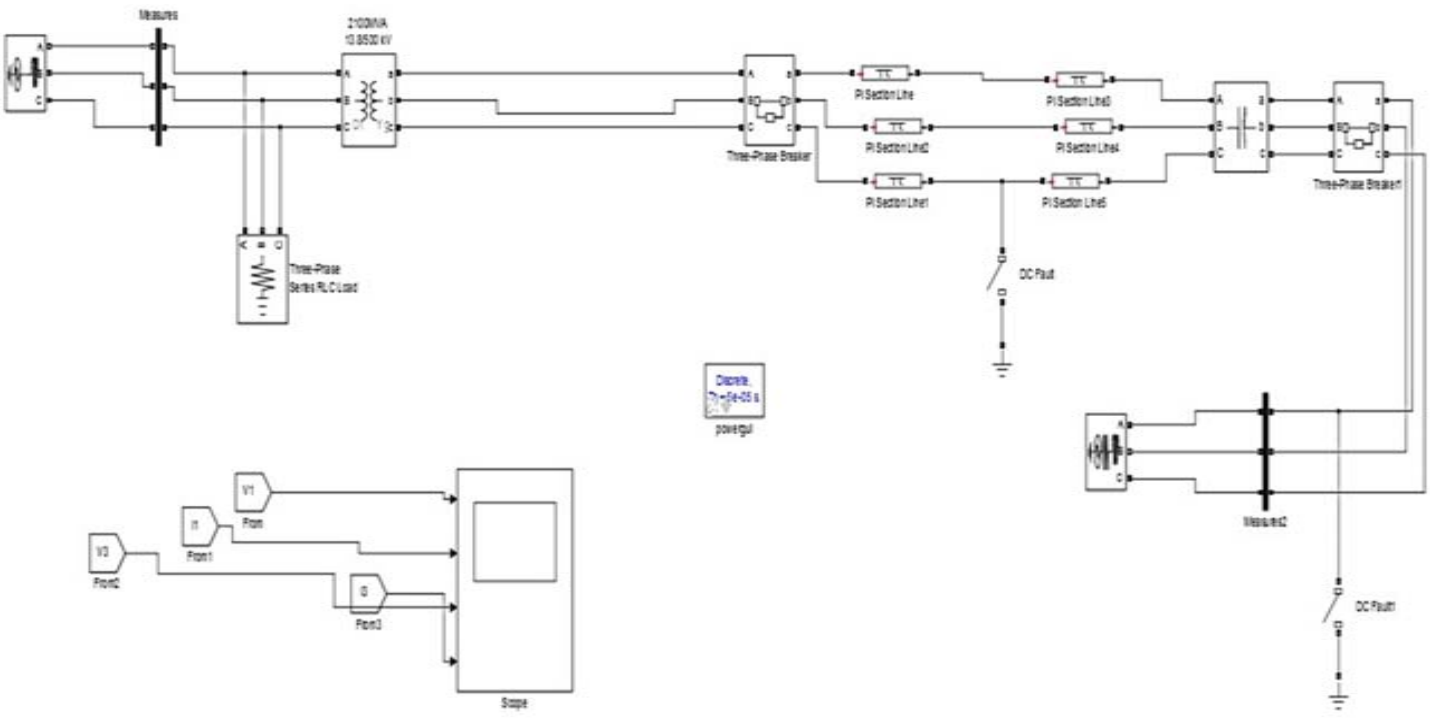

Fig. 2. The HVAC power transmission system simulink model

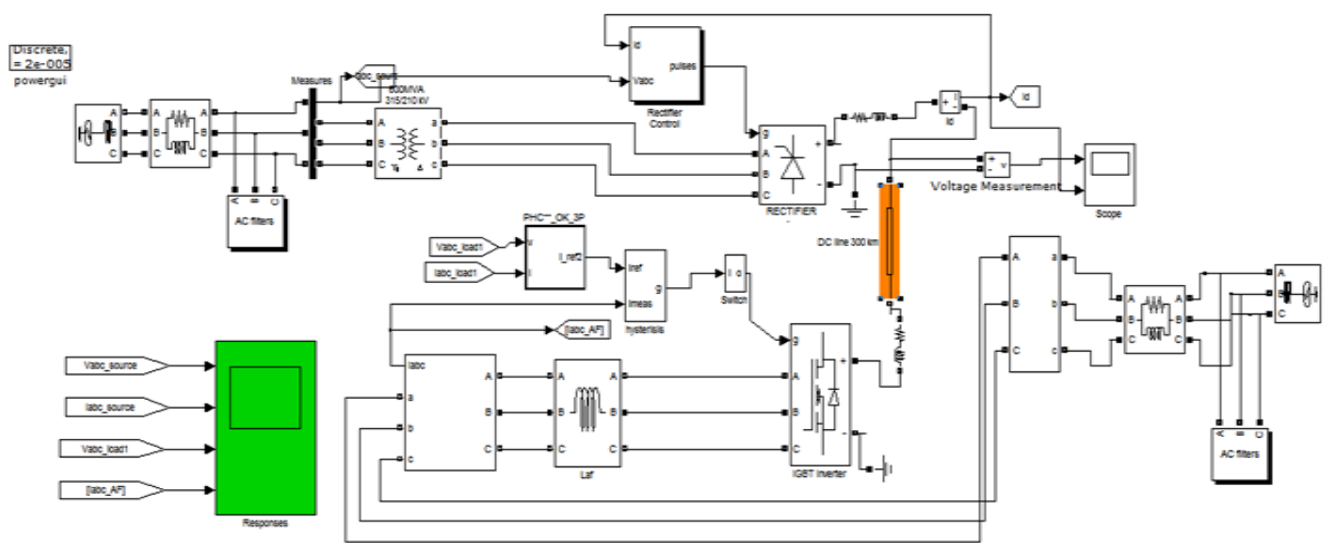

Fig. 3. The HYBRID HVDC system Simulink model
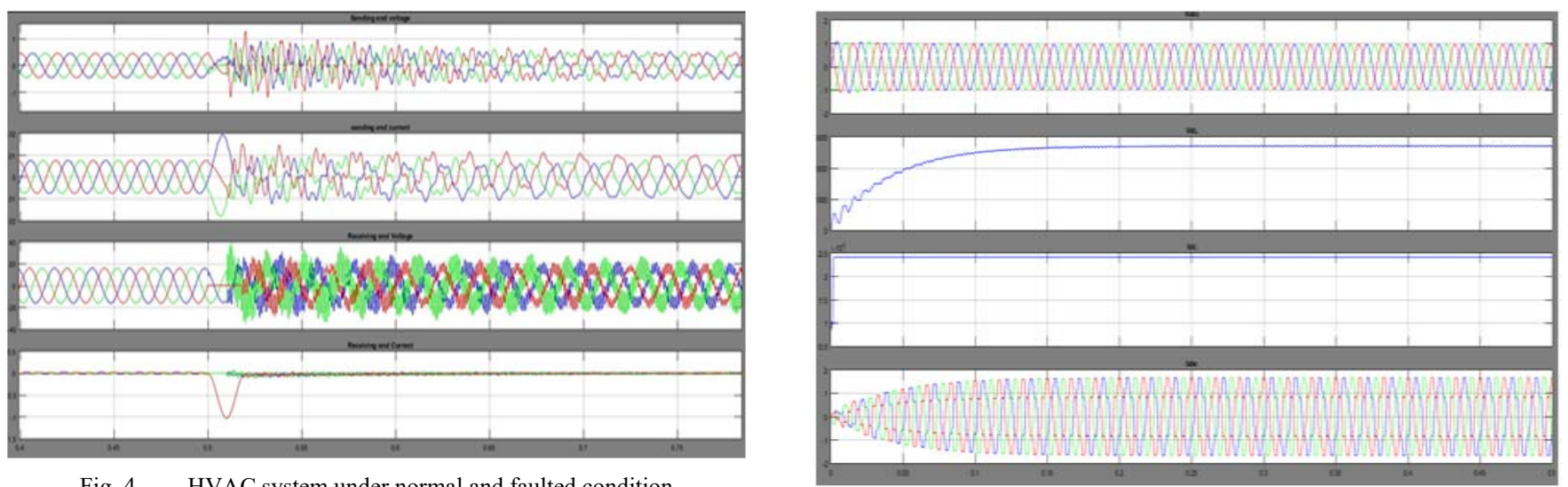

Fig. 4. HVAC system under normal and faulted condition 
Fig. 5. HVDC system with fault

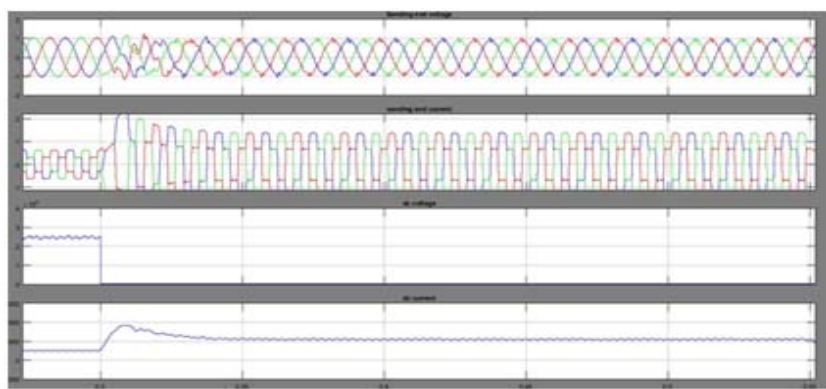

Fig. 6. HVDC system without fault
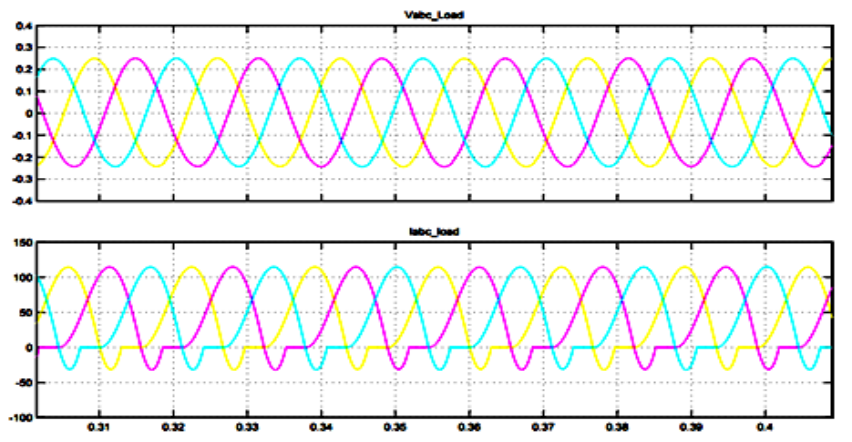

Fig. 7. Steady state current and voltage of AC side of HVDC system

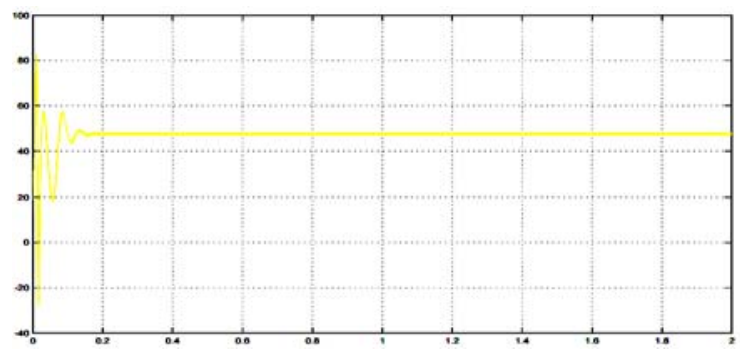

Fig. 8. Steady state analysis- DC side waveform
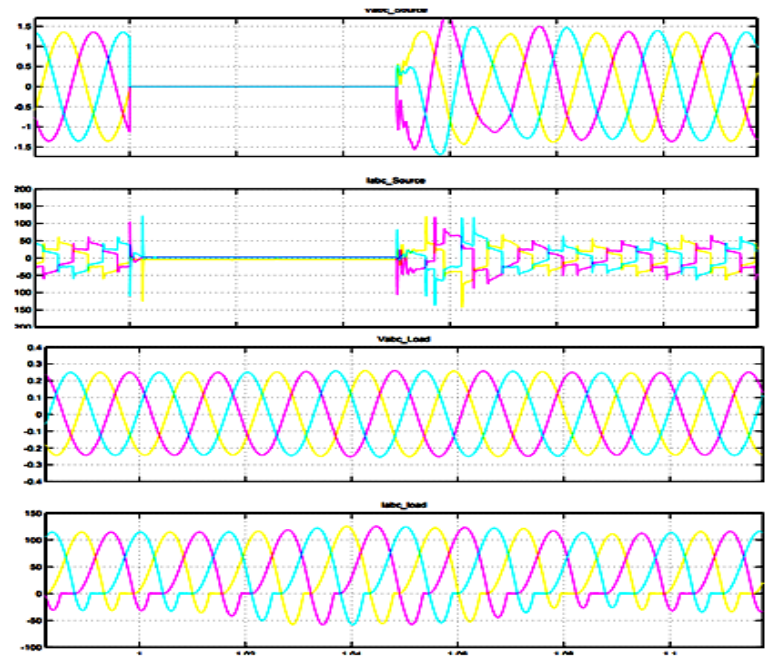

Fig. 9. Three phase fault in HVDC-AC side performance

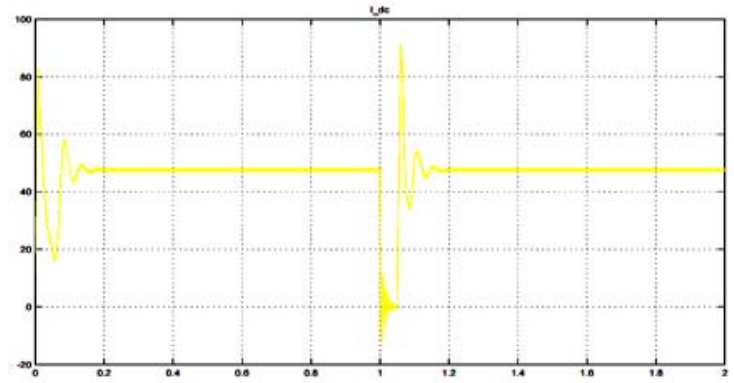

Fig. 10. Three phase fault - DC side waveforms

A considerable improvement in the transient performances of MI-HVDC systems under faulted conditions using HYBRID HVDC technology can be observed. The proposed hybrid system provides a good solution for MI-HVDC system inverting into a weak AC network. The simulation studies show that the VSC system makes the conventional LCC system less susceptible to commutation failure. As a part of future work, fault current for all types of symmetric and asymmetric faults in different sections should be analyzed, enabling a complete comparative study of HVAC and HVDC grid systems, along with their cost analysis. The developed hybrid model can be further extended to MTDC systems replacing the Hybrid HVDC model with independent LCC and VSC HVDC units under different ends.

\section{REFERENCES}

[1] G. Shilpa, P. Manohar, "Hybrid HVDC System for Multi-infeed Applications", 2013 International Conference on Emerging Trends in Communication, Control, Signal Processing \& Computing Applications (C2SPCA), pp. 1 - 5, India, October 10-11, 2013

[2] M. P. Bahrman,B. K. Johnson, "The ABCs of HVDC Transmission Technologies", Power and Energy Magazine, Vol. 5, No. 2, pp. 32-44, 2007

[3] Y.A. Garces, E. A. Cano-Plata, A. J. Ustariz-Farfan, "Hybrid simulation: an active power filter case study", Revista Ingenieria E Investigacion, Vol. 31, pp 76-80, 2011 
[4] V. Behravesh, N. Abbaspour, "New Comparison of HVDC and HVAC Transmission system", International Journal of Engineering Innovation \& Research, Vol. 1, No. 3, pp. 300-304, 2012

[5] P. Fischer, J. Pan, K. Srivastava, W. Wang, C. Hong, "Case study of a multi-infeed HVDC system”, Powercon 2008, New Delhi, India, October 12-15, 2008

[6] P.d Fischer, G. Asplund, E. Jansson, “Aspects on infeed of multiple HVDC into one ac network", ABB Power System, HVDC Division, Sweden, April 2012

[7] G. Asplund, "Electric Transmission System in Change", Key Notes, IEEE Power Electronics Specialists Conference, Greece, June, 2008

[8] C. Guo, Y. Zhang, A. M. Gole, C. Zhao, "Analysis of dual-infeed HVDC with LCC-HVDC and VSC-HVDC," IEEE Transactions on Power Electronics, Vol. 27, No. 3, pp. 1529-1537, 2012

[9] A.Tirupati Rao, P. Ramana, P. Kanata Rao, "Modeling of CIGRE HVDC Benchmark System in MATLAB/SIMULINK", International Journal of Education and Applied Research, Vol. 4, No. Spl-1, pp. 112115,2014

[10] J. Kreusel, "Integrated AC/DC Transmission Systems-Benefits of Power Electronics Safety And Sustainability of Power Supply" Power System Computation Conference, UK, July, 2008

[11] O. Kotb, A hybrid HVDC transmission system supplying a passive load, M.Sc. Thesis, Department of Electrical and Computer Engineering, Oshawa, Ontario, Canada, 2010 